\title{
An LC-MS/MS method for stable isotope dilution studies of $\gamma$-carotene bioefficacy and vitamin A status in humans
}

\author{
Anthony Oxley ${ }^{1}$, Philip Berry ${ }^{2}$, Joseph Cowell ${ }^{3}$, Michael Hall ${ }^{3}$, John Hesketh ${ }^{4}$, Georg Lietz ${ }^{1}$ \\ and Alan V. Boddy ${ }^{2}$ \\ ${ }^{1}$ Human Nutrition Research Centre, School of Agriculture, Food and Rural Development, ${ }^{2}$ Northern Institute for Cancer \\ Research, ${ }^{3}$ School of Chemistry, ${ }^{4}$ Institute for Cell and Molecular Biosciences, Newcastle University, UK
}

Isotope dilution is currently the most accurate technique in humans to determine vitamin A status and bioavailability/bioconversion of provitamin A carotenoids ${ }^{(1)}$. However, limits of MS detection, coupled with extensive isolation procedures, have hindered investigations of physiologically-relevant doses of stable isotopes ${ }^{(2)}$. We developed a sensitive liquid chromatography-tandem-mass spectrometry (LCMS/MS) analytical method to study the plasma response from co-administered oral doses of $2 \mathrm{mg}\left[{ }^{13} \mathrm{C}_{10}\right]-\beta$-carotene and $1 \mathrm{mg}\left[{ }^{13} \mathrm{C}_{10}\right]-$ retinyl acetate in human subjects. A single one-phase solvent extraction, with no saponification or purification steps, left retinyl esters intact for determination of intestinally-derived retinol in chylomicrons versus retinol from the liver bound to retinol-binding protein (RBP).
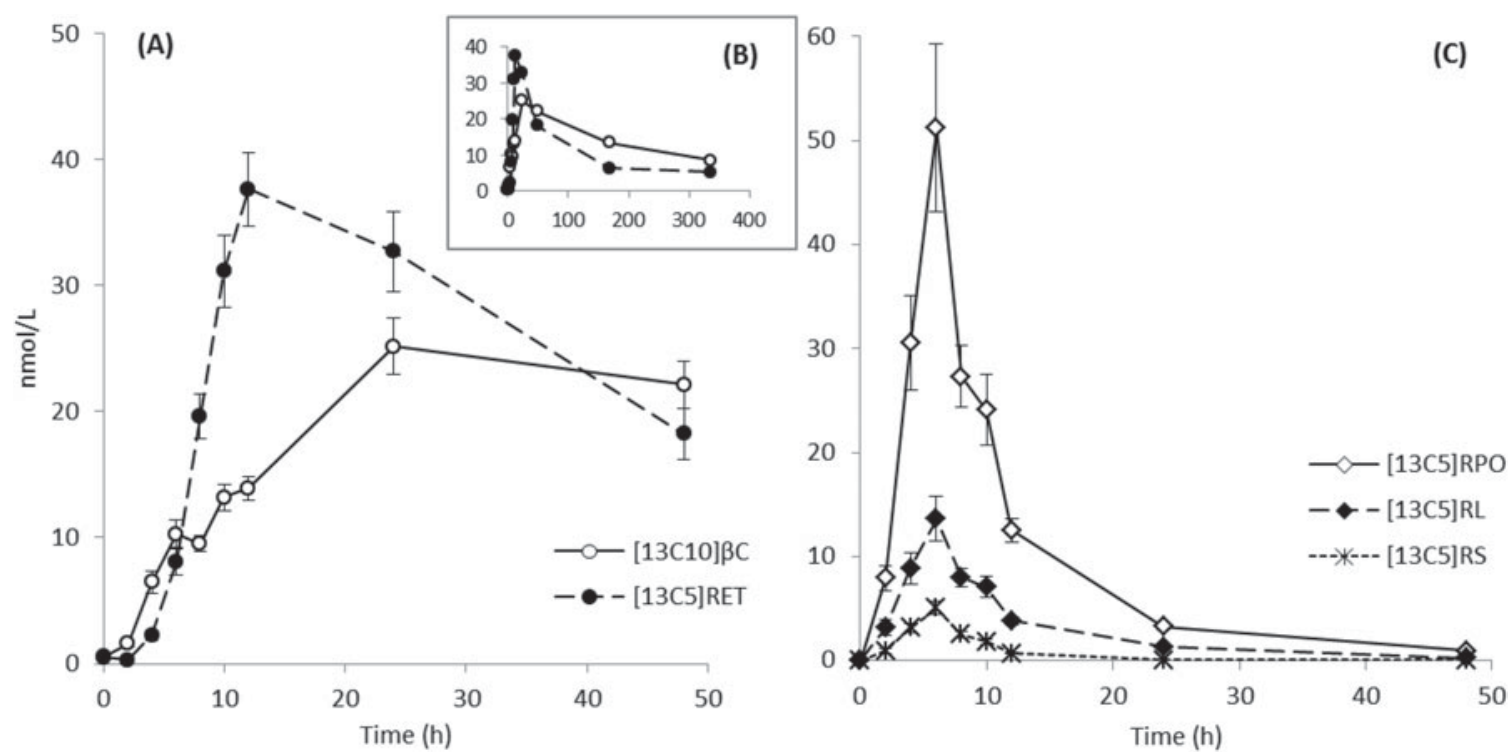

Fig. 1. Quantitative LC-MS/MS analysis of mean plasma responses from 45 human subjects ( + /- SEM) over the first $48 \mathrm{~h}(\mathrm{~A}, \mathrm{C})$ and whole 14 day study period (B). Administered $\left[{ }^{13} \mathrm{C}_{10}\right]-\beta$-carotene $(\beta \mathrm{C})$ and resulting $\left[{ }^{13} \mathrm{C}_{5}\right]$ cleavage products (RET, retinol; RL, retinyl linoleate; RPO, retinyl palmitate + oleate; RS, retinyl stearate) are shown in $\mathrm{A}$, B, and $\mathrm{C}$.

Co-administration of $\left[{ }^{13} \mathrm{C}_{10}\right]$-retinyl acetate with $\left[{ }^{13} \mathrm{C}_{10}\right]-\beta$-carotene not only acts as a reference dose for inter-individual variations in absorption and chylomicron clearance rates, but also allows for simultaneous determination of an individual's vitamin A status. In summary, this new analytical method enables the detection of physiological concentrations of provitamin A carotenoids, their cleavage products as well as preformed vitamin A for a period of at least 2 weeks post dose administration and allows high throughput analysis due to its simplicity and short run times.

This work was supported by the BBSRC.

1. Furr HC, Green MH, Haskell M et al. (2005) Public Health Nutrition 8(6), 596-607.

2. van Lieshout M, West CE and van Breemen RB (2003) Am J Clin Nutr 77(1), 12-28. 